\title{
USULAN WAKTU PENGGANTIAN OPTIMUM KOMPONEN MESIN GAS ENGINE (PRECHAMBER GAS VALVE) DENGAN MODEL AGE-BASED REPLACEMENT DI PT. XYZ
}

\author{
Kusnadi $^{1 *}$, Taryana ${ }^{2}$ \\ ${ }^{1,2}$ Program Studi Teknik Industri Fakultas Teknik Universitas Singaperbangsa Karawang \\ Jl. H.S. Ronggowaluyo, Teluk Jambe Timur, Karawang, Jawa Barat 41361 \\ *Email : tikuk.kusnadi@yahoo.com
}

Diterima: 25 September 2015

Direvisi: 20 Desember 2015

Disetujui: 6 Januari 2016

\begin{abstract}
ABSTRAK
PT. XYZ adalah perusahaan yang bergerak di bidang manufaktur perakitan sepeda motor, visinya menjadi perusahaan yang leading di bidang tersebut. Berdasarkan hasil wawancara dan pengamatan langsung di perusahaan, untuk perawatan mesin Gas Engine perusahaan telah menerapkan kegiatan maintenance dengan konsep Planned Maintenance dan Unplanned maintenance, Tingkat kepentingan perawatan untuk mesin Gas Engine ini sangat tinggi mengingat bahwa Gas Engine merupakan sumber pasokan listrik untuk menunjang kegiatan produksi sehari-hari. Kerusakan komponen terbesar ada pada komponen Prechamber Gas Valve, hal tersebut dikarenakan tidak adanya perlakuan perawatan khusus terhadap komponen tersebut karena beberapa faktor, sementara komponen tersebut sangat berpengaruh pada kondisi mesin, yang bisa mengancam stop line produksi. Model matematis metode Age Based Replacement adalah metode yang tepat dalam memecahkan masalah tersebut, dimana dengan metode ini akan didapat interval waktu optimum untuk melakukan pergantian part prechamber gas valve untuk meningkatkan kinerja mesin. Berdasarkan hasil perhitungan, diperoleh interval penggantian komponen mesin Gas Engine (Prechamber Gas Valve) yang optimum adalah 6.547 jam dengan unit cost sebesar Rp. 1.316 per Jam
\end{abstract}

Kata kunci: Rencana Pemeliharaan, Unplanned Maintenance, prechamber Gas Valve, Gas Engine, Penggantian Metode Umur Berdasarkan

\begin{abstract}
PT. XYZ is a company engaged in manufacturing motorcycle assembly, vision of becoming the leading company in this field. Based on interviews and direct observation in the company, for machinery maintenance Gas Engine companies have implemented maintenance activities with the concept of Planned Maintenance and Unplanned maintenance, level of importance of maintenance for machinery Gas Engine is very high considering that the Gas Engine is a source of power supply to support production activities day -day. Damage was biggest component in the component prechamber Gas Valve, it is because there is no special maintenance treatment of those components due to several factors, while the component is very influential on the condition of the engine, which could threaten the production line stop. The mathematical model Age Based Replacement method is the correct method to solve the problem, which will be obtained by this method is the optimum time interval to make the turn part prechamber gas valve to improve engine performance. Based on calculations, the replacement interval of engine components Gas Engine (prechamber Gas Valve) optimum is 6547 hours with the unit cost of Rp. 1,316 per Hour
\end{abstract}

Keywords : Planned Maintenance, Unplanned Maintenance, Prechamber Gas Valve, Gas Engine, Metode Age Based Replacement 


\section{PENDAHULUAN}

Dengan semakin meningkatnya persaingan pada bidang manufaktur, maka perusahaan harus melakukan perbaikan secara continuous untuk menjaga kestabilan perusahaan dalam mencapai visinya. Salah satu faktor yang perlu diperhatikan adalah sistem maintenance perusahaan. Karena mesin-mesin merupakan asset perusahaan yang perlu dijaga ketersediaannya (availability) untuk mendukung kelancaran proses produksi. Oleh sebab itu, perlu dijaga dan ditingkatkan kehandalan mesin sehingga dapat mendukung kelancaran proses produksi.

Ketersediaan mesin pada saat produksi tanpa adanya breakdown sangat penting karena mengingat ketatnya persaingan di dunia manufaktur khususnya sepeda motor, yang mengutamakan kualitas produk dan kecepatan ketersediaan produk.

Kerusakan yang dialami mesin Gas Engine bervariasi, mulai dari (sistem kontrol mesin, bahan bakar mesin, pembakaran mesin, pendinginan mesin, dan pelumasan mesin), berikut ini adalah garfik banyaknya kerusakan mesin Gas Engine

Tabel 1. Data kerusakan mesin Gas Engine

\begin{tabular}{|c|c|c|c|c|c|c|}
\hline \multicolumn{7}{|c|}{ Data Kerusakan Mesin ( Gas Engine ) } \\
\hline \multirow{5}{*}{ Jenis kerusakan } & \multicolumn{5}{|c|}{$\begin{array}{c}\text { Total } \\
\text { Breakdown/Tahun }\end{array}$} & \multirow{5}{*}{$\begin{array}{l}\text { To } \\
\text { tal }\end{array}$} \\
\hline & 2 & 2 & 2 & 2 & 2 & \\
\hline & 0 & 0 & 0 & 0 & 0 & \\
\hline & 1 & 1 & 1 & 1 & 1 & \\
\hline & 1 & 2 & 3 & 4 & 5 & \\
\hline $1 \quad C y l$ Dev & 3 & 2 & 2 & & & \\
\hline $\begin{array}{l}\text { High(precham } \\
\text { ber rusak) }\end{array}$ & $\begin{array}{l}3 \\
2\end{array}$ & $\begin{array}{l}2 \\
8\end{array}$ & $\begin{array}{l}2 \\
1\end{array}$ & $\begin{array}{l}1 \\
9\end{array}$ & $\begin{array}{l}2 \\
0\end{array}$ & $\begin{array}{c}12 \\
0\end{array}$ \\
\hline 2 Meassuring & & 1 & & & & \\
\hline . signal Failure & 1 & 2 & 6 & 7 & 2 & 28 \\
\hline $\begin{array}{ll}3 & \text { Temperatur } \\
. & \text { High }\end{array}$ & 2 & 1 & 4 & 1 & 2 & 10 \\
\hline $\begin{array}{l}4 \text { In Out Chanel } \\
\text {. Failure }\end{array}$ & 1 & 0 & 0 & 1 & 0 & 2 \\
\hline $\begin{array}{ll}5 & \text { Gas Mixer } \\
. & \text { Abnormal }\end{array}$ & 0 & 2 & 0 & 1 & 0 & 3 \\
\hline $\begin{array}{ll}7 & \text { Relay } \\
. & \text { Abnormal }\end{array}$ & 2 & 5 & 4 & $\begin{array}{l}1 \\
0\end{array}$ & 3 & 24 \\
\hline
\end{tabular}

Sumber (PT. XYZ, 2015)

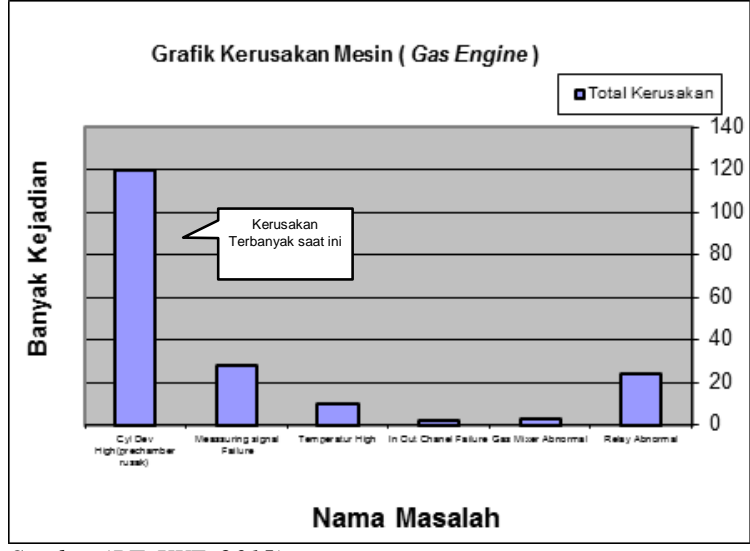

Sumber (PT. XYZ, 2015)

Gambar 1. Grafik kerusakan mesin gas engine

Dan dari kerusakan-kerusakan tersebut, jenis kerusakan terbanyak yang membuat kinerja Gas Engine tidak maksimal adalah dalam sistem pembakaran mesin Gas Engine untuk jenis masalah Cylinder Deviation High , komponen mesin yang mengalami kerusakan terbanyak yaitu Prechamber Gas Valve. Prechamber Gas Valve merupakan komponen dalam pembakaran mesin, yang berfungsi sebagai pemasok bahan bakar gas ke ruang bakar (Ignition Point), sehingga ketika part tersebut mengalami kegagalan fungsi, maka pembakaran mesin akan mengalami abnormal, dan akan menyebabkan Gas Engine mati tibatiba atau trip. Sementara sistem perawatan terhadap Prechamber Gas Valve saat ini, hanya dilakukan penggantian part baru ketika kondisi part tersebut mengalami kerusakan (Gas Engine mati tiba-tiba), karena tidak adanya pemeriksaan rutin dan penggantian rutin, serta posisi part Prechamber Gas Valve yang sulit di deteksi fisiknya.

Berdasarkan latar belakang tersebut, diperlukan suatu usulan sistem pencegahan terhadap kerusakan mesin Gas Engine atau kegiatan preventive maintenance terhadap mesin sehingga resiko terjadinya breakdown mesin dapat diminimalkan. Selain itu, dengan adanya sistem maintenance yang baik dan terencana, maka logistik ketersediaan spare parts juga dapat diatur agar tetap tersedia pada saat yang dibutuhkan, dengan jumlah yang dibutuhkan sesuai dengan spesifikasi. Jika tidak segera dilakukan perbaikan terhadap permasalahan tersebut, maka semakin lama sejalan dengan bertambahnya usia mesin akan menimbulkan kerugian materi yang lebih besar lagi akibat penurunan kehandalan mesin. 
Tujuan pemecahan masalah adalah untuk meminimumkan terjadinya breakdown mesin Gas Engine di PT. XYZ, Dengan cara :

1. Menerapkan model matematik untuk menentukan interval waktu preventive maintenance yang optimum untuk komponen mesin Gas Engine (Prechamber Gas Valve).

2. Mencari solusi model sesuai distribusi kerapatan probabilitas dari interval waktu preventive maintenance pada sistem yang diamati.

\section{TINJAUAN PUSTAKA}

\section{Perawatan (Maintenance)}

Perawatan adalah sebuah operasi atau aktivitas yang harus dilakukan secara berkala dengan tujuan untuk melakukan pergantian kerusakan peralatan dengan resources yang ada. Perawatan juga ditujukan untuk mengembalikan suatu sistem pada kondisinya agar dapat berfungsi sebagaimana mestinya, memperpanjang usia kegunaan mesin, dan menekan failure sekecil mungkin. Manajemen perawatan dapat digunakan untuk membuat sebuah kebijakan mengenai aktivitas perawatan, dengan melibatkan aspek teknis dan pengendalian manajemen ke dalam sebuah program perawatan. Pada umumnya, semakin tingginya aktivitas perbaikan dalam sebuah sistem, kebutuhan akan manajemen dan pengendalian di perawatan menjadi semakin penting. Berikut adalah sembilan pendekatan untuk membuat sebuah program perawatan yang efektif:

1. Mengidentifikasi kekurangan eksisting.

2. Membuat tujuan akhir dari program.

3. Menetapkan skala prioritas.

4. Menetapkan parameter untuk pengukuran performansi.

5. Menetapkan rencana jangka pendek dan juga jangka panjang.

6. Sosialisasi perencanaan terhadap bagianbagian yang terkait.

7. Implementasi perencanaan.

8. Laporan berkala.

9. Pemeriksaan kemajuan secara rutin. 10.

Adapun klasifikasi dari perawatan mesin adalah:

\section{Preventive Maintenance}

Preventive Maintenance adalah salah satu komponen penting dalam aktivitas perawatan (maintenance). Preventive maintenance adalah aktivitas perawatan yang dilakukan sebelum terjadinya kegagalan atau kerusakan pada sebuah sistem atau komponen, dimana sebelumnya sudah dilakukan perencanaan dengan pengawasan yang sistematik, deteksi, dan koreksi, agar sistem atau komponen tersebut dapat mempertahankan kapabilitas fungsionalnya. Beberapa tujuan dari preventive maintenance adalah mendeteksi lebih awal terjadinya kegagalan/kerusakan, meminimalisasi terjadinya kegagalan dan meminimalkan kegagalan produk yang disebabkan oleh kerusakan sistem.

Ada empat faktor dasar dalam memutuskan penerapan preventive maintenance:

1. Mencegah terjadinya kegagalan.

2. Mendeteksi kegagalan.

3. Mengungkap kegagalan tersembunyi (hidden failure).

4. Tidak melakukan apapun karena lebih efektif daripada dilakukan pergantian.

Dengan mengidentifikasi keempat faktor dalam melaksanakan preventive maintenance, terdapat empat kategori dalam mengspesifikasikan preventive maintenance. Keempat ketegori tersebut adalah sebagai berikut:

1. Time-Directed (TD) adalah perawatan yang diarahkan secara langsung pada pencegahan kegagalan atau kerusakan

2. Condition-Directed (CD) adalah perawatan yang diarahkan pada deteksi kegagalan atau gejala-gejala kerusakan.

3. Failure-Finding (FF) adalah perawatan yang diarahkan pada penemuan kegagalan tersembunyi.

4. Run-to-Failure (RTF) adalah perawatan yang didasarkan pada pertimbangan untuk menjalankan komponen hingga rusak karena pilihan lain tidak memungkinkan atau tidak menguntungkan dari segi ekonomi.

\section{Predictive Maintenance}

Predictive maintenance didefinisikan sebagai pengukuran yang dapat mendeteksi degradasi sistem, sehingga penyebabnya dapat dieliminasi atau dikendalikan tergantung pada kondisi fisik komponen. Hasilnya menjadi indikasi kapabilitas fungsi sekarang dan masa depan.

Pada dasarnya, predictive maintenance berbeda dengan preventive maintenance dengan berdasarkan kebutuhan perawatan pada kondisi actual mesin dari pada jadwal yang telah ditentukan. Dapat dikatakan bahwa preventive 
maintenance bersifat time-based, seperti pergantian oli setiap 3000 jam kerja. Hal ini tidak memperhatikan performa dan kondisi aktual mesin. Jika dilakukan pemeriksaan, mungkin penggantian oli dapat diperpanjang hingga 5000 jam kerja. Hal ini yang membedakan antara preventive maintenance dengan predictive maintenance dimana predictive maintenance menekankan kegiatan perawatan pada kondisi aktual.

\section{Time Directed Maintenance}

Time directed maintenance dapat dilakukan apabila variabel waktu dari komponen atau sistem diketahui. Kebijakan perawatan yang sesuai untuk diterapkan pada time directed maintenance adalah periodic maintenance dan on-condition maintenance. Periodic maintenance (hard time maintenance) adalah perawatan pencegahan yang dilakukan secara terjadwal dan bertujuan untuk mengganti sebuah komponen atau system berdasarkan interval waktu tertentu. On-condition maintenance merupakan kegiatan perawatan yang dilakukan berdasarkan kebijakan operator.

\section{Condition Based Maintenance}

Condition Base Maintenance merupakan aktivitas perawatan pencegahan yang dilakukan berdasarkan kondisi tertentu dari suatu komponen atau sistem, yang bertujuan untuk mengantisipasi sebuah komponen atau sistem agar tidak mengalami kerusakan. Karena variable waktunya tidak pasti diketahui, kebijakan yang sesuai dengan kondisi tersebut adalah predictive maintenance. Predictive Maintenance merupakan suatu kegiatan perawatan yang dilakukan dengan menggunakan sistem monitoring, misalnya analisis dan komposisi gas.

\section{Failure Finding}

Failure Finding merupakan kegiatan perawatan pencegahan yang bertujuan untuk mendeteksi kegagalan yang tersembunyi, dilakukan dengan cara

memeriksa fungsi tersembunyi (hcidden function) secara periodik untuk memastikan kapan suatu komponen mengalami kegagalan.

\section{Run to Failure}

Run to Failure tergolong sebagai perawatan pencegahan karena faktor ketidaksengajaan yang bisa saja terjadi dalam beberapa peralatan. Disebut juga sebagai no schedule maintenance karena dilakukan jika tidak ada tindakan pencegahan yang efektif dan efisien yang dapat dilakukan, jika dilakukan tindakan pencegahan terlalu mahal atau dampak kegagalan tidak terlalu esensial (tidak terlalu berpengaruh).

\section{Corrective Maintenance}

Corrective Maintenance merupakan kegiatan perawatan yang dilakukan untuk mengatasi kegagalan atau kerusakan yang ditemukan selama masa waktu preventive maintenance. Pada umumnya, corrective maintenance bukanlah aktivitas perawatan yang terjadwal, karena dilakukan setelah sebuah komponen mengalami kerusakan dan bertujuan untuk mengembalikan kehandalan sebuah komponen atau sistem ke kondisi semula.

Perawatan dilakukan dengan jadwal yang teratur, sehingga kadang-kadang disebut sebagai "perawatan yang direncanakan" atau "perawatan yang dijadwal". Fungsi penting dari cara perawatan jenis ini adalah menjaga kondisi operasional peralatan serta meningkatkan kehandalannya. Tujuannya adalah menghilangkan penyebab-penyebab kerusakan sebelum kerusakan terjadi. Perawatan yang terjadwal selalu lebih ekonomis daripada perawatan yang tidak terjadwal.

Pekerjaan perawatan preventif ini dilakukan dengan mengadakan inspeksi, pelumasan dan pengecekan peralatan seteliti mungkin. Frekuensi inspeksi ditetapkan menurut tingkat kepentingan mesin, tingkat kerusakan dan kelemahan mesin. Inspeksi berkala ini sangat membantu pengecekan untuk menemui penyebab-penyebab yang menimbulkan kerusakan, dan juga untuk mempermudah usaha perbaikannya melalui tahapantahapannya.

Perawatan preventive mempunyai tujuan sebagai berikut:

a. Untuk mencapai tingkat kesiapan industri yang maksimum dengan mencegah kerusakan dan mengurangi periode waktu perbaikan menjadi seminimum mungkin.

b. Menjaga kondisi mesin sebaik mungkin untuk mempertahankan produk yang berkualitas tinggi.

c. Memperkecil tingkat kerusakan dan menjaga nama baik industri.

d. Menjamin keselamatan pekerja.

e. Menjaga industri pada tingkat efisiensi produksi yang maksimum.

f. Mencapai semua tujuan tersebut dengan cara yang sangat ekonomis. 
Berikut ini adalah beberapa keuntungan penting dari program perawatan preventive yang dilaksanakan dengan baik diantaranya :

a. Waktu terhentinya produksi menjadi berkurang.

b. Berkurangnya pembayaran kerja lembur bagi tenaga perawatan.

c. Berkurangnya waktu untuk menunggu peralatan yang dibutuhkan.

d. Berkurangnya pengeluaran biaya untuk perbaikan.

e. Penggantian suku cadang yang direncanakan dapat dihemat kebutuhannya, sehingga suku cadang selalu tersedia di gudang setiap waktu.

f. Keselamatan kerja operator lebih tinggi karena berkurangnya kerusakan.

Pekerjaan perawatan harus dilakukan berdasarkan pertimbangan dari berbagai faktor yang aman dan menguntungkan. Berikut ini adalah suatu contoh prosedur yang dapat dipakai untuk melakukan perawatan pada mesin.

Perawatan harian dapat dilakukan oleh operatornya sendiri. Sebelum mulai bekerja pada mesin, terlebih dahulu operator melakukan pembersihan dan pelumasan terhadap mesin yang akan dipakainya. Untuk pelaksanaan ini, industri mengeluarkan instruksi yang ditujukan kepada para operator untuk melakukan perawatan mesin. Instruksi ini harus ditaati dengan sungguh-sungguh.

Sedangkan pelaksanaan perawatan periodiknya, bisa ditangani oleh tenaga perawatan yang sudah dilatih secara khusus untuk tugas tersebut. Periode waktu perawatan ini perlu ditentukan berdasarkan pengalaman terdahulu untuk mempercepat keterangannya. Dalam hal ini instruksi pengoperasian mesin harus diikuti dengan benar oleh operator. Adanya kejadian yang tidak normal atau kelainan-kelainan yang timbul pada mesin dengan segera dilaporkan kepada tenaga perawatan agar gangguan dapat cepat diatasi. Tindakan perbaikan harus segera dilakukan, jangan sampai menunda waktu.

\section{METODE PENELITIAN} Jenis Penelitian

Jenis penelitian pada tugas akhir ini adalah action research, karena penelitian ini hanya dilakuka $\mathrm{n}$ sampai pengajuan usulan sistem perawatan dan belum diaplikasikan pada perusahaan. Pengumpulan data primer yaitu data interval waktu penggantian komponen mesin Gas Engine (Prechamber Gas Valve), dikumpulkan dengan mencatat tanggal dilakukan penggantian sampai memperoleh jumlah interval sebanyak 100 buah dari 20 Pcs Prechamber Gas Valve. Data-data lainnya yang berhubungan dengan model yang akan diterapkan diperkirakan sesuai dengan parameter yang diperlukan. Pengumpulan data dilakukan dengan cara observasi langsung, sedangkan pengolahan data berisikan perhitungan dengan menggunakan metode Age Replacement.

Pengumpulan data diantaranya:

1. Sistem Kerja Mesin

Sistem kerja mesin berupa sitematik penggunaan mesin sebagai pemasok aliran listrik.

2. Karakteristik Sistem Perawatan

Karakteristik sistem perawatan ini merupakan penjelasan sistem perawatan yang ada saat ini pada mesin Gas Engine.

3. Pemilihan Sistem Kritis

Pemilihan komponen kritis yaitu komponen mesin yang memiliki frekuensi kerusakan tertinggi yaitu komponen masin Prechamber Gas Valve.

4. Data Kerusakan Komponen Mesin Terpilih

Data kerusakan komponen mesin terpilih pada tahun 2011-2015.

5. Pemilihan Komponen Kritis

Komponen kritis dipilih dengan menggunakan analisis pareto. Komponenkomponen yang terpilih yaitu komponen yang memiliki efek atau dampak mesin mati tiba-tiba

6. Data Waktu Antar Kerusakan Komponen Kritis

Data waktu antar kerusakan komponen kritis diuraikan berdasarkan tanggal kerusakan komponen kritis dan running hours mesin

7. Data Ongkos Penggantian Kerusakan dan Pencegahan

Ongkos yang dikeluarkan diantaranya Ongkos Komponen Pengganti, Ongkos Operator, Keuntungan yang hilang.

8. Uji Distribusi Waktu Antar Kerusakan Uji distribusi waktu antar kerusakan dengan menggunakan uji Goodness Of Fit.

9. Perhitungan Parameter Distribusi Waktu Antar Kerusakan

Perhitungan parameter distribusi seuai dengan hasil uji Godness of Fit. 
10. Perhitungan model matematis untuk optimum preventive maintenance.

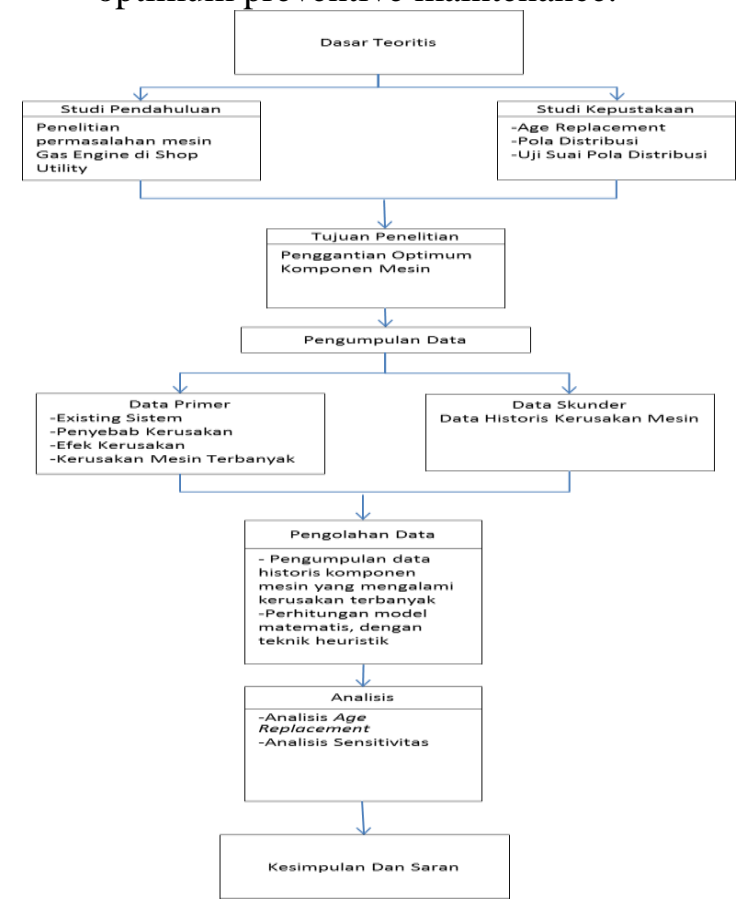

\section{HASIL DAN PEMBAHASAN}

Berdasarkan hasil rekapitulasi jumlah breakdown yang diakibatkan komponen mesin yang rusak, maka jenis kerusakan Cyl Dev High (Prechambr Gas Valve Rusak) adalah komponn mesin yang paling sering mengalami kerusakan yang di tunjukkan di Grafik 4.4. Pada tabel 4.15. berikut menunjukkan interval kerusakan komponen Prechamber Gass Valve

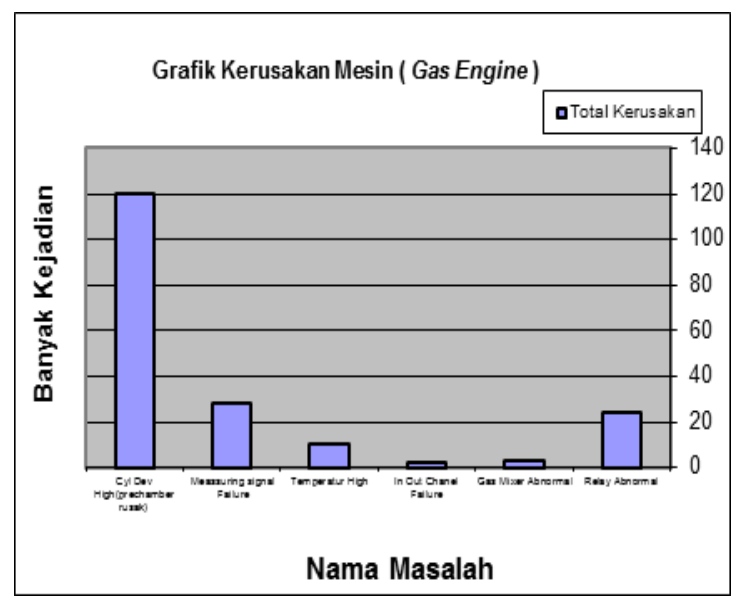

Data tersebut diolah hingga memperoleh tabel distribusi frekuensi, dan kemudian di uji suai data tersebut

Dan berikut ini adalah proses pengolahan data tersebut: $\operatorname{Max}=6443, \quad$ Min $=8110$

$$
\begin{aligned}
\text { Rentangan/Range } & =\text { Max-Min } \\
& =1667
\end{aligned}
$$

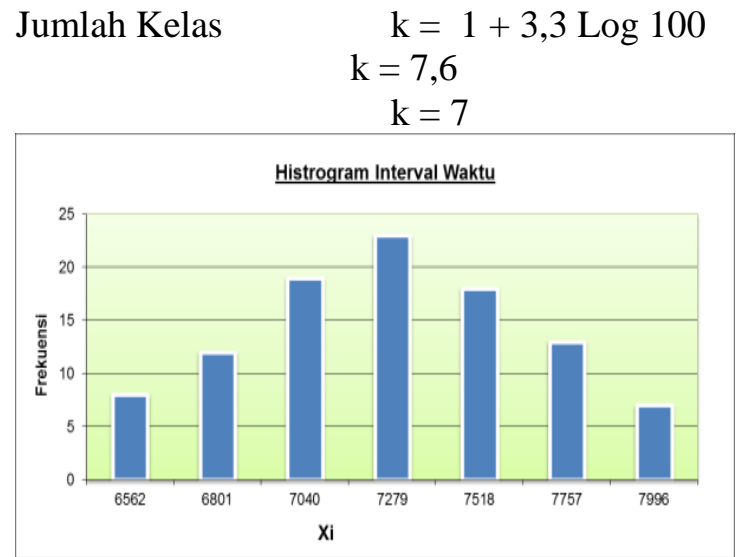

Panjang Kelas

$$
=239
$$

Test Goodness Of Fit dengan Uji KolmogorovSmirnov

Ho : Pdf Interval Waktu berdistribusi Normal $\mathrm{Hi}$ : Pdf Interval Waktu tidak berdistribusi Normal

\begin{tabular}{|c|c|c|c|c|c|c|c|c|c|c|c|c|c|c|c|}
\hline \multicolumn{16}{|c|}{ Perhitungan Uji Suai distribusis Normal ( Kolmogorov-Smimov) } \\
\hline \multirow{2}{*}{ k } & \multirow{2}{*}{ B } & \multirow{2}{*}{ A } & \multicolumn{2}{|c|}{ Kelas hiteral } & \multirow{2}{*}{ rekuensi } & \multirow{2}{*}{ Fkum } & \multirow{2}{*}{$x_{i}$} & \multirow{2}{*}{ Fixi } & \multirow{2}{*}{$X \cdot \dot{X}$} & \multirow{2}{*}{$(X \cdot \dot{x})^{2}$} & \multirow{2}{*}{$z=(X X \dot{X}) S D$} & \multirow{2}{*}{$S(x)$} & \multirow{2}{*}{$F(X)$} & \multirow{2}{*}{$|F(x) \cdot S(x)|$} & \multirow[t]{10}{*}{ W1-a } \\
\hline & & & \begin{tabular}{|l|l}
$B B$ & \\
\end{tabular} & $B A$ & & & & & & & & & & & \\
\hline 1 & 6443 & \begin{tabular}{ll|l}
66881 & 6 \\
\end{tabular} & 6442,566 & 6681,5 & 8 & 8 & 6562 & 52496 & \begin{tabular}{|l|l|}
712222 \\
\end{tabular} & $507.257,33$ & $\mid(1,84)$ & 0,008 & 0,03 & 0,05 & \\
\hline 2 & 6682 & 69206 & 66881,569 & 9920,5 & 12 & 20 & 6801 & 81612 & $(473,22)$ & 2223997,17 & $(1,22)$ & \begin{tabular}{|l|}
0,2 \\
\end{tabular} & 0,11 & 0,09 & \\
\hline 3 & 6921 & 715964 & 6920,571 & 1159,5 & 19 & 39 & 7040 & 133760 & (234,22) & 54.859,01 & $(0,61)$ & 0,39 & 0,27 & 0,12 & \\
\hline 4 & 7160 & 73987 & \begin{tabular}{|l|l}
7159,573 \\
\end{tabular} & 7398,5 & 23 & 62 & 7279 & 167417 & \begin{tabular}{|l|}
4,78 \\
\end{tabular} & \begin{tabular}{|l}
22,85 \\
\end{tabular} & 0,01 & $0,0,62$ & 0,50 & 0,12 & \\
\hline 5 & 7399 & \begin{tabular}{l|l}
7637 & 77 \\
\end{tabular} & 7398,576 & 637,5 & 18 & 80 & 7518 & 135324 & \begin{tabular}{|l|l|}
243,78 \\
\end{tabular} & $59,428,69$ & 0,63 & 0,8 & 0,74 & 0,06 & \\
\hline 6 & 7638 & 78767 & 76037,578 & 876,5 & 13 & 93 & 7757 & 100841 & \begin{tabular}{|l|}
482,78 \\
\end{tabular} & $233.076,53$ & 1,25 & 0,93 & 0,89 & 0,04 & \\
\hline \multirow[t]{6}{*}{7} & 7877 & 81157 & 7876,581 & 3115,5 & 7 & 100 & 7996 & 55972 & \begin{tabular}{|l|}
721,78 \\
\end{tabular} & $520.966,37$ & 1,87 & 1 & \begin{tabular}{|l|}
0,97 \\
\end{tabular} & 0,03 & \\
\hline & & $\Sigma$ & & & 100 & & & 727422 & & & Staisisic Value & eDmax & & 0,12 & \\
\hline & & & Ho: datab b & Derdistibibus & osi Nomal & & Xrata & $7.274,2$ & & Kesimplan: & & & & & \\
\hline & & & Hi: data id & dak berdis. & istribusi iko & & & 386,9 & & $\begin{array}{l}\text { Ho: diterima, } \\
\text { Karena Dmax }\end{array}$ & $\begin{array}{l}\text { atwa adat berr } \\
\text { WI-a }\end{array}$ & ridstibus & i Normal & & \\
\hline & & & & & & & bl & & 000 & & & & & & \\
\hline & & & & & & $=0,134$ & & & & & & & & & \\
\hline
\end{tabular}

Tabel 2. Uji Suai dengan uji KolmogorovSmirnov

Pdf dikatakan berdistribusi normal jika Thitung $<$ W $1-\alpha$

Dari hasil perhitungan diperoleh:

Thitung $=0,12$ dan $\mathrm{W} 1-\alpha=0,136$; maka Thitung $<$ W1- $\alpha$ dan Ho Diterima

Dengan demikian dapat dietrima bahwa Pdf berdistribusi Normal

Sesuai rekomendasi Duffuaa ( 1999 ) untuk sistem sederhana dapat menggunakan model "Age-based Preventive Replacement" Kebijakan type I berikut adalah notasi-notasi yang akan digunakan:

$C_{p} \quad=$ Ongkos Pemeliharaan Preventive

$C_{f}=$ Ongkos Pemeliharaan Breakdown (failure)

$f(t)=$ time-to-failure probability density function 
$F(t)$ $=$ time-to-failure cumulative

distribution $=\int_{0}^{t} f(t) \cdot d t$

$r(t)=$ failure rate function

$N\left(t_{p}\right)=$ Jumlah kegagalan (failure) pada interval $\left(0, t_{p}\right), \mathrm{N}\left(t_{\perp} p\right)$ adalah variabel random.

$H\left(t_{p}\right)=$ Jumlah kegagalan yg diharapkan (expected) pada interval $\left(0, t_{p}\right)$

$R(t)=$ fungsi reliabilitas atau survival

$M\left(t_{p}\right)=$ Nilai yg diharapkan (expected value) dari $p d f f(t)$ yg terpotong (truncated) di $t_{p}$

$M\left(t_{p}\right)=\int_{-\infty}^{t_{p}} t \cdot f(t) \cdot d t /\left(1-R\left(t_{p}\right)\right)$

EC $\left(t_{p}\right)=$ Expected cost per cycle

$\operatorname{UEC}\left(t_{p}\right)=$ Expected cost per unit time

Tujuan model adalah menetapkan $t_{p}$ optimum, artinya, pemeliharaan preventive dilakukan setelah peralatan/sistem beroperasi secara terus menerus selama waktu $t_{p}$. Model menentukan $t_{p}$ yang meminimasi ongkos total preventive dan breakdown per satuan waktu.

$\operatorname{UEC}\left(t_{p}\right)=\frac{\text { total expected cost per cycle }}{\text { expected cycle length }}$

Total expected cost per cycle adalah ongkos preventive maintenance ditambah ongkos breakdown:

$$
E C\left(t_{p}\right)=\quad C_{p} \cdot R\left(t_{p}\right)+C_{f} \cdot\left(1-R\left(t_{p}\right)\right)
$$

$R\left(t_{p}\right)$ adalah probabilitas peralatan/sistem tetap beroperasi sampai waktu $t_{p}$

Expected cycle length atau panjang siklus (waktu) yang diharapkan adalah expected length dari pemeliharaan preventive plus expected length dari failure cycle.

Expected cycle length $=t_{p} \cdot R\left(t_{p}\right)+M\left(t_{p}\right)[1$

- $\left.R\left(t_{p}\right)\right]$

Dimana $: M\left(t_{p}\right)=\frac{\int_{-\infty}^{L_{p}} t_{f} f(t) \cdot d t}{\left(1-R\left(t_{p}\right)\right)}$

Sehingga

$\operatorname{UEC}\left(t_{p}\right)=$

$\frac{C_{p} \cdot R\left(t_{p}\right)+C_{f} \cdot\left(1-R\left(t_{p}\right)\right)}{t_{p} \cdot R\left(t_{p}\right)+M\left(t_{p}\right) \cdot\left[1-R\left(t_{p}\right)\right]}$

Biaya pemeliharaan preventive untuk penggantian Prechamber Gas Valve adalah ongkos yang terdiri dari biaya Operator/tenaga kerja ditambah dengan biaya ongkos sparepart.

Diperkirakan mencapai Rp8.370.000.00,-

Sehingga $C p=R p$. 8.370.000.00,- per siklus.

Biaya pemeliharaan breakdown adalah biaya resiko terjadi mati listrik total ketika dilakukan perbaikan mesin terhadap komponen Prechamber Gas Valve, akibat mesin mati mendadak, biaya tersebut diperkirakan Rp. 16.448.500.00,-

Sehingga $C f=R p$. 16.448.500.00,- per siklus.

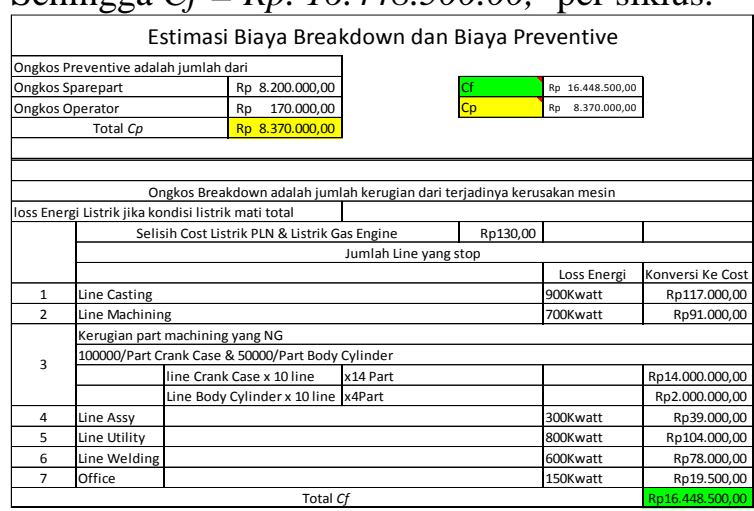

Fungsi kerapatan probabilitas telah diuji pada Tabel 2. berdistribusi normal sehingga bisa dinyatakan sebagai berikut :

$f(t)$

$=$

$\frac{1}{\sigma \sqrt{2} \pi} e^{-\frac{1}{2}\left(\frac{t-\beta}{\sigma}\right)^{2}}-\infty \leq t \leq$

$\infty$ (pdf distribusinormal)

karena,

$\mu=\bar{x}=7274,2$

$\sigma=\sigma_{x}=386,9$

Maka:

$f(t)=\left\{\begin{array}{cc}\frac{1}{386,9 \sqrt{2} \pi} e^{-\frac{1}{2}\left(\frac{t-7274,2}{886,9}\right)^{2}} & 0 \leq t \leq 8500 \mathrm{Jam}, \\ 0 & \text { otherwise }\end{array}\right.$

$F(t)$
$\left\{\begin{array}{rl}\int_{0}^{t} \frac{1}{386,9 \sqrt{2 \pi}} e^{-\frac{1}{2}\left(\frac{t-7274,3}{886,9}\right)^{2} d t} & 0 \leq t \leq 8500 \mathrm{Jam} \\ 1 & \text { if } t \geqq 8500 \mathrm{Jam}\end{array}\right.$

$R(t)=1-F(t)$

Dengan menggunakan distribusi normal baku $f(z)$, dapat dibuat tabel $F(t)$ untuk $6443 \leq \mathrm{t}$ $\leq 8500$, selanjutnya dengan menggunakan persamaan $4.1 \mathrm{~s} / \mathrm{d} 4.5$ maka $\operatorname{UEC}\left(t_{p}\right)$ bisa dihitung untuk setiap $t_{p}$ juga dengan bantuan tabel distribusi normal baku , dari hasil 
perhitungan UEC (tp) kemudian dibuatkan grafik yang menggambarkan kurva $\operatorname{UEC}(t p)$ :

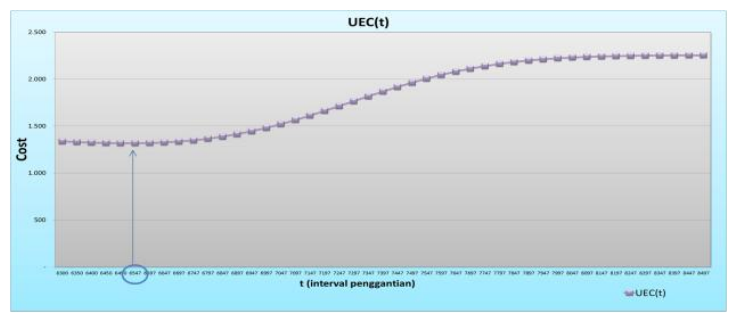

Dari gambar tersebut diperoleh, interval penggantian komponen mesin Gas Engine (Prechamber Gas Valve) yang optimum adalah 6547 jam dengan unit cost sebesar Rp. 1.316 per Jam

\section{KESIMPULAN DAN SARAN}

Adapun kesimpulan yang dapat ditarik berdasarkan hasil pembahasan adalah sebagai berikut:

1. Jenis kerusakan yang paling sering terjadi pada mesin Gas Engine adalah Temperature Deviation High yang diakibatkan oleh kerusakan komponen mesin Gas Engine (Prechamber Gas Valve)

2. Model untuk menentukan interval waktu pemeliharaan preventive dapat ditetapkan dengan minimasi ongkos total per satuan waktu sebagai berikut:

Min

$$
\operatorname{UEC}\left(t_{p}\right)=\frac{C_{p} \cdot R\left(t_{p}\right)+C_{f} \cdot\left(1-R\left(t_{p}\right)\right)}{t_{p} \cdot R\left(t_{p}\right)+M\left(t_{p}\right) \cdot\left[1-R\left(t_{p}\right)\right]}
$$

Subject to $\mathrm{a} \leq \mathrm{t} \leq \mathrm{b}$

3. Fungsi Kerapatan Probabilitas (Probability Density Function) untuk interval penggantian komponen berdistribusi normal dengan : $\mu=\bar{x}=7.274,22$

$\sigma=386,4$

4. Berdasarkan hasil perhitungan dengan cara heuristik, diperoleh interval penggantian komponen mesin Gas Engine (Prechamber Gas Valve) yang optimum adalah 6.547 jam dengan unit cost sebesar Rp. 1.316 per Jam

5. Kondisi aktual sekarang penggantian terhadap konmponen mesin Gas Engine ( Prechamber Gas Valve, dilakukan penggantian komponen tersebut setelah kondisi komponen tersebut rusak dan mesin mati mendadak, dengan diketahui interval waktu pemeliharaan preventive yang optimum, dapat dibuat jadwal pemeliharaan yang pasti, tanpa harus menunggu hasil monitor indikator kinerja peralatan/sistem.

\section{DAFTAR PUSTAKA}

Duffuaa, S O, Raouf, A and Campbell J D , Planning and Control of Maintenance System : Modelling and Analysis, John Wiley and Sons, New York, 1999.

"http://deriz.weebly.com/uploads/1/7/8/4/17847 63/metode_perawatan_mesin.docx", Makalah Perawatan Dan Pemeliharaan Mesin Industri, 2014.

Winarno, DIKTAT KULIAH : STATISTIKA INDUSTRI 2,Fakultas Teknik, Teknik Industri, UNSIKA, 2013.

Ni Luh Putu Hariastuti, Aplikasi Ages Replacement Methods Dalam Menentukan Optimasi Penjadwalan Perawatan Kendaraan, Jurusan teknik Industri, Institute Teknologi Adhi Tama Surabaya, 2013. 